\title{
In vitro culture technique for Cryptocaryon irritans, a parasitic ciliate of marine teleosts
}

\author{
Tomoyoshi Yoshinaga ${ }^{1, *}$, Kousuke Akiyama ${ }^{1}$, Sayoko Nishida ${ }^{1}$, Motoyuki Nakane ${ }^{2}$, \\ Kazuo Ogawa ${ }^{1}$, Hitomi Hirose ${ }^{2}$
}

${ }^{1}$ Graduate School of Agricultural and Life Sciences, The University of Tokyo, Yayoi 1-1-1, Bunkyo-ku, Tokyo 113-8657, Japan

${ }^{2}$ College of Bioresource Science, Nihon University, Kameino 1866, Fujisawa, Kanagawa 252-8510, Japan

\begin{abstract}
A medium for the in vitro culture of Cryptocaryon irritans, which is an obligatorily parasitic ciliate of marine teleosts and causes 'white spot disease', was developed. The medium consisted of a layer of cultured fish cells (FHM), with an agarose gel layer covering the cell layer. The agarose gel contained $0.22 \%$ agarose, $10 \%$ fetal calf serum, 100 I.U. ml ${ }^{-1}$ Penicillin G potassium and $100 \mu \mathrm{g}$ $\mathrm{ml}^{-1}$ streptomycin sulphate. Theronts of C. irritans transformed to trophonts and grew to $180 \mu \mathrm{m}$ in mean length in the medium, although they gradually decreased in number. When trophonts fully developed in medium were transferred into seawater $4 \mathrm{~d}$ after inoculation, approximately $70 \%$ of them transformed to encysted tomonts and released theronts. When fish were challenged with theronts obtained from in vitro-raised parasites, approximately $40 \%$ of the theronts were recovered from fish, indicating comparative infectivity of in vitro-raised theronts to those of in vivo-raised theronts. This is the first report that $C$. irritans fully developed in vitro and its entire life cycle was completed without a host fish.
\end{abstract}

KEY WORDS: Cryptocaryon irritans $\cdot$ Ciliophora $\cdot$ In vitro culture $\cdot$ White spot disease $\cdot$ Marine fish

\section{INTRODUCTION}

Cryptocaryon irritans is an obligatorily parasitic ciliate of marine teleosts and causes 'white spot disease'. The life cycle consists of 4 developmental stages: parasitic trophonts growing in size without cell division within the epithelial layer of the skin and gills of the host fish, protomonts leaving hosts and later being encysted in seawater, encysted tomonts in which repeated cell fissions occur, and theronts released from tomonts into seawater (Colorni 1985, Colorni \& Burgess 1997, Dickerson 2006). This parasite is cosmopolitan in distribution, ranging from tropical to subtropical waters, and is very common in public or private aquaria and mariculture facilities (Colorni \& Burgess 1997). Mass mortalities of fishes caused by the parasite often result in large economic losses in mariculture.
Despite economic losses and stock mortality caused by Cryptocaryon irritans, few effective treatments or control measures have been developed for the parasite, especially for food fish cultured in open waters, although several chemotherapeutic agents are known to be effective for ornamental fish in closed environments (Colorni \& Burgess 1997, Dickerson 2006). For net cage culture situations, the transfer of net cages containing infected fish to more open waters is mainly used and indeed is the only method currently available (Yoshinaga 2001). However, difficulties in the early detection of the parasite and in keeping areas pristine prior to transfer often make the therapy ineffective and unfeasible.

The absence of an in vitro culture technique is a major obstacle in studies aimed at developing treatments and control measures for Cryptocaryon irritans. In most experiments, the parasite has to be maintained 
and propagated in vivo using live fish, as for Ichthyophthirius multifiliis, the freshwater counterpart of C. irritans, which has a life cycle very similar to that of C. irritans. In vivo propagation of the 2 parasitic ciliates is labour intensive and can be unreliable. Development of in vitro propagation techniques for both parasites has, therefore, been sought. Ekless \& Matthews (1993), Nielsen \& Buchmann (2000), Xu et al. (2000) and Yambot \& Song (2004) have tried to develop propagation techniques for $C$. irritans and $I$. multifiliis. Some of these authors have succeeded in transforming theronts into trophonts and some have succeeded in growing them to a certain extent in artificial media, but development to the tomont and theront stages has not been accomplished under in vitro conditions for either species.

In the present study, we developed a medium for the in vitro culture of Cryptocaryon irritans and examined the survival and growth of the parasite in the new medium. The development of in vitro-raised parasites in seawater and the infectivity of theronts derived from the in vitro-raised parasites were also examined.

\section{MATERIALS AND METHODS}

Fish and parasites. A porcupine puffer Diodon holocanthus infected with Cryptocaryon irritans was obtained from a local pet shop and used as a source of C. irritans. The parasite was propagated in vivo using black mollies (Poecilia sp. hybrid, probably P. latipinna, 3 to $4 \mathrm{~cm}$ in body length) as hosts, and protomonts were collected from infected black mollies following Yoshinaga \& Dickerson (1994). Collected protomonts were washed 5 times with seawater, and incubated in seawater in Petri dishes $\left(10 \mathrm{~cm}^{2}\right)$ at $25^{\circ} \mathrm{C}$; 500 to 1000 protomonts were placed in $4 \mathrm{ml}$ seawater in each dish, and seawater was replaced daily with fresh seawater. Seawater, filtered with $0.45 \mu \mathrm{m}$ filters and supplemented with 100 I.U. $\mathrm{ml}^{-1}$ Penicillin G potassium and $100 \mu \mathrm{g} \mathrm{ml}^{-1}$ streptomycin sulphate, was used for washing and incubation of protomonts and tomonts throughout this study, unless otherwise stated. When placed in seawater, protomonts transformed to encysted tomonts within several hours and subsequently began to release theronts in 4 to $6 \mathrm{~d}$. These theronts were used for the in vitro culture.

In vitro culture. A double-layered medium consisting of a cell layer and an agarose gel layer was developed and used regularly for the in vitro culture of Cryptocaryon irritans. The medium mimics the epithelial layer of fish skin, which harbours the parasite. FHM cells, an epithelial cell line originating from the fat head minnow Pimephales promelas, cultured in Leibovits L-15 medium supplemented with $10 \%$ fetal calf serum (FCS), 100 I.U. ml $\mathrm{m}^{-1}$ Penicillin G potassium and $100 \mu \mathrm{g} \mathrm{ml}^{-1}$ streptomycin sulphate, were inoculated in cell culture dishes $\left(10 \mathrm{~cm}^{2}\right)$ at a density of $2.5 \times$ $10^{5}$ cells $\mathrm{cm}^{-2}$. After the cells settled on dish bottoms, forming cell layers, a $4 \mathrm{ml}$ solution of ultra-low-melting-point agarose (Sigma, Catalogue No. A-0701) dissolved in L-15 medium supplemented with FCS and antibiotics was distributed on the cell layer in each dish and gelatinized at $4{ }^{\circ} \mathrm{C}$; the final concentrations of the constituents were $0.22 \%$ agarose, $9 \%$ FCS, 90 I.U. $\mathrm{ml}^{-1}$ Penicillin $\mathrm{G}$ potassium and $90 \mu \mathrm{g} \mathrm{ml} \mathrm{m}^{-1}$ streptomycin sulphate $(0.5 \%$ agarose solution, 50 parts; double-strength L-15 medium, 50 parts; FCS, 10 parts; 100-fold strength of Penicillin G potassium and streptomycin sulphate dissolved in $0.85 \% \mathrm{NaCl}$ solution, 1 part). The concentrations of agarose were optimized by our preliminary experiments (data not shown). A theront suspension containing 100 to 300 theronts in $15 \mu \mathrm{l}$ of seawater was inoculated at the centre of the cell layer beneath the gel with $200 \mu \mathrm{l}$ micropipette tips and incubated at $25^{\circ} \mathrm{C}$. Parasites in the medium were observed and counted with an inverted phase-contrast microscope at Hour 4 PI (post-inoculation) and subsequently every $24 \mathrm{~h}$, and photographed for further measurements of their size. This experiment was carried out in triplicate. In total, 20 to 30 trophonts were measured from each dish, and the measurements from 3 dishes were pooled to obtain the mean and frequency distribution in parasite length.

Trophonts and tomont-like cysts that transformed from inoculated theronts in the medium were recovered from the medium using pipettes on Day 2 to $7 \mathrm{PI}$; gel layers were detached from dish bottoms by putting sterile seawater below the gels and removed using pipettes, prior to the recovery. The trophonts and tomont-like cysts obtained from the medium were washed, incubated in $2 \mathrm{ml}$ of seawater supplemented with antibiotics in Petri dishes at $25^{\circ} \mathrm{C}$, and examined with an inverted phase-contrast microscope daily for $10 \mathrm{~d}$ to observe release of theronts. The experiments were carried out in triplicate. For comparison, protomonts obtained from 3 mollies infected in the propagation aquaria were pooled, washed and incubated in seawater in Petri dishes in the same way. Tomonts and theronts derived from parasites recovered from in vitro cultures and experimentally infected fish were photographed for further measurements; theronts were fixed in $1 \%$ formalin before measurement to stop their movement.

Large-scale in vitro culture. For large-scale cultures, medium was constituted in large culture dishes $\left(57 \mathrm{~cm}^{2}\right)$, in which $25 \mathrm{ml}$ of the same L-15 medium (supplemented with agarose, FCS and antibiotics) as that used in regular-scale culture was layered on FHM cell layers $\left(2.5 \times 10^{5}\right.$ cells $\left.\mathrm{cm}^{-2}\right)$. Theronts released from 
tomonts that were obtained from the fish were concentrated by centrifugation (2000 $g, 10 \mathrm{~s})$, and a theront suspension was inoculated at 6 points evenly distributed in each dish and incubated at $25^{\circ} \mathrm{C}$. This experiment was carried out twice using different batches and volumes of the theront suspension; $15 \mu$ l of suspension containing 2700 theronts was inoculated at 6 points in each dish (16 200 theronts dish ${ }^{-1}$ or 280 theronts $\mathrm{cm}^{-2}$ ) in the first experiment, and $30 \mu \mathrm{l}$ of suspension containing 1280 theronts was inoculated in each of 2 dishes ( 7700 theronts dish ${ }^{-1}$ or 140 theronts $\mathrm{cm}^{-2}$ ) in the second experiment. Trophonts raised in the 2 dishes in the second experiment were collected and pooled on
Day $4 \mathrm{PI}$, and incubated in seawater at $25^{\circ} \mathrm{C}$ to obtain tomonts and theronts. Theronts released from tomonts obtained in the second experiment were used for experimental infection of fish.

Experimental infection of fish with theronts produced by in vitro culture. Black mollies were experimentally infected with theronts that were released from tomonts obtained in the second largescale in vitro culture experiment to investigate the infectivity of theronts produced by in vitro culture. Three back mollies were exposed to 2600 theronts within $3 \mathrm{~h}$ after their release, in $300 \mathrm{ml}$ of seawater without antibiotics, in a beaker for $1 \mathrm{~h}$. Subsequently,
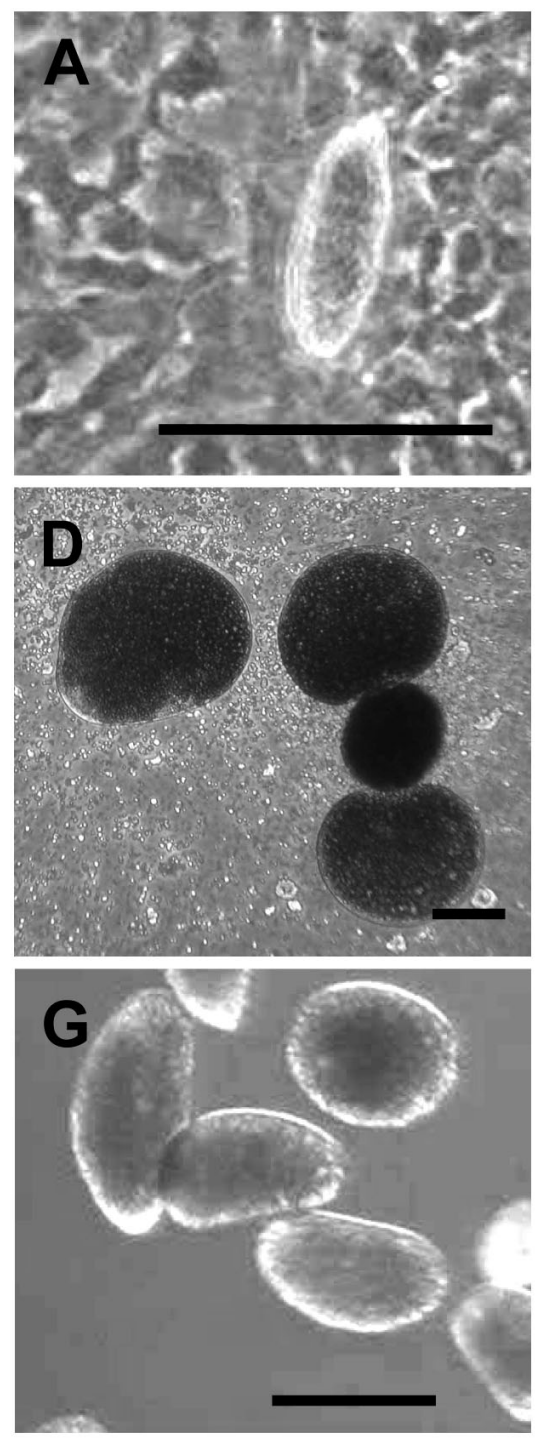
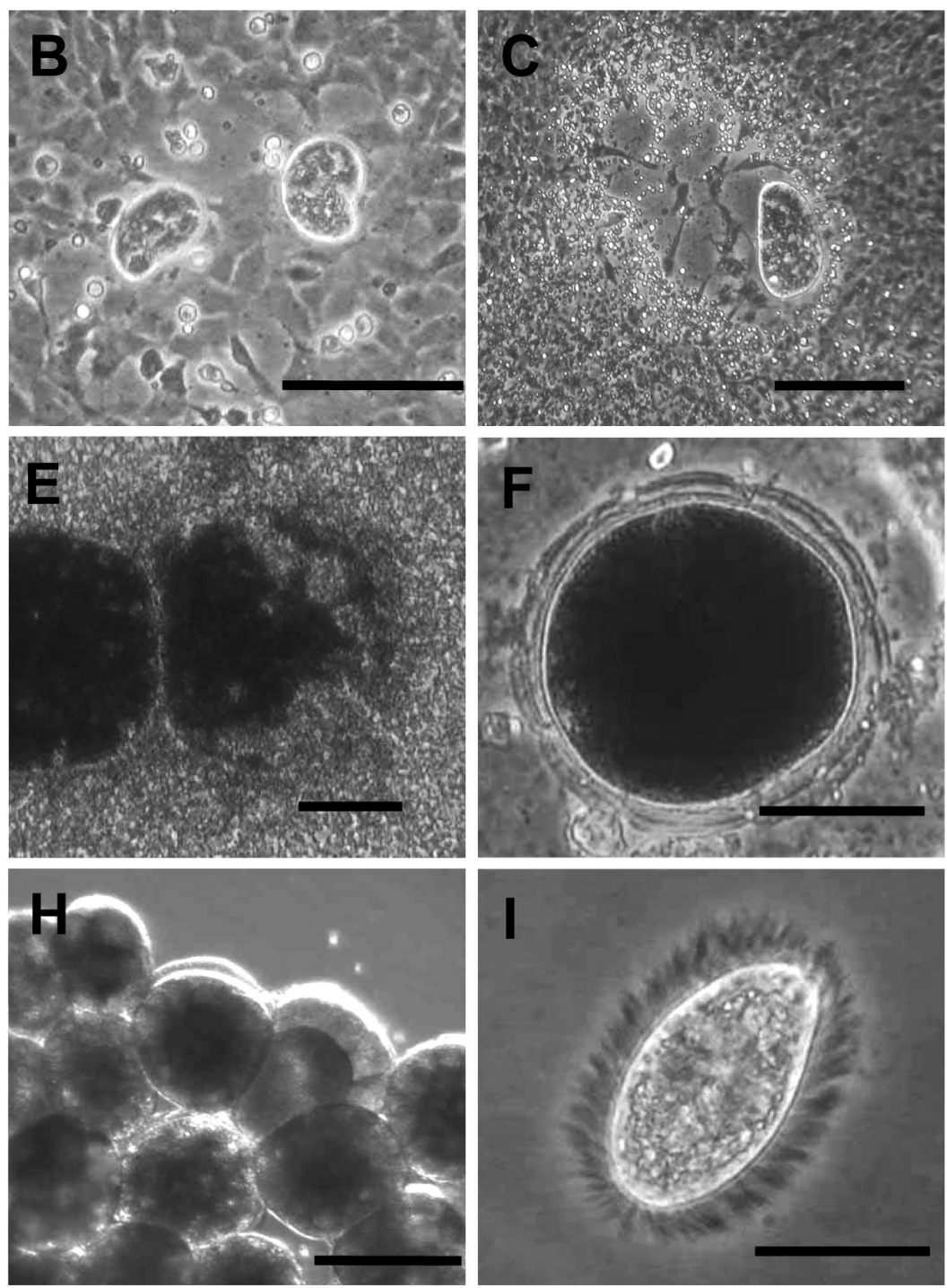

Fig. 1. Cryptocaryon irritans. Illustrations in the double-layered medium (A to F) and further development after transfer to seawater (G to I). (A) Theront just after inoculation, (B) trophont at Hour 4 PI, (C) trophont in a hollow-like empty space, (D) fully developed trophonts, (E) ruptured trophont (right), (F) tomont-like cyst formed in a medium, (G) protomonts just after transfer from medium to seawater, $(\mathrm{H})$ encysted tomonts produced with the in vitro culture technique and (I) theront released from a tomont produced by the in vitro culture technique. Scale bars $=100 \mu \mathrm{m}(\mathrm{A}, \mathrm{B}, \mathrm{F}), 200 \mu \mathrm{m}(\mathrm{C}, \mathrm{D}, \mathrm{E}, \mathrm{G}, \mathrm{H})$, and $25 \mu \mathrm{m}(\mathrm{I})$ 
they were individually transferred and reared at $25^{\circ} \mathrm{C}$ in $450 \mathrm{ml}$ of seawater with gentle aeration; seawater was replaced daily with fresh seawater. Parasites that left the fish 3 to $4 \mathrm{~d}$ after exposure were then found at the bottom of the water column, collected and counted.

Image analysis. Photo-images of parasites were taken with a CCD camera attached to an inverted microscope and analyzed with Scion Image (Scion) image analysis software for measurements.

\section{RESULTS}

Immediately after the inoculation into medium, theronts of Cryptocaryon irritans showed a teardroplike or spindle-like appearance and were swimming actively between the cell layer and gel layer (Fig. 1A). By Hour 4 PI, most of the theronts transformed to trophonts (Fig. 2); they became rounder and began to slowly crawl between the layers (Fig. 1B). After transformation, trophonts grew gradually. As trophonts grew, FTM cells around them detached from the dish bottom and empty hollows were sometimes formed around trophonts (Fig. 1C). Structures very similar to the detached FTM cells were frequently observed within trophonts, suggesting that the parasites were eating detached FTM cells. Although trophonts decreased in number day by day (Fig. 2), they showed a clear increase in size until Day 4 PI. Trophonts grew as large as $180 \mu \mathrm{m}$ in mean length, and several > $300 \mu \mathrm{m}$ in length appeared (Figs. 1D \& 3). Subsequently, many of the trophonts ruptured in the medium (Fig. 1E). Simultaneously, a small number of trophonts transformed in medium to tomont-like cysts, having a cyst

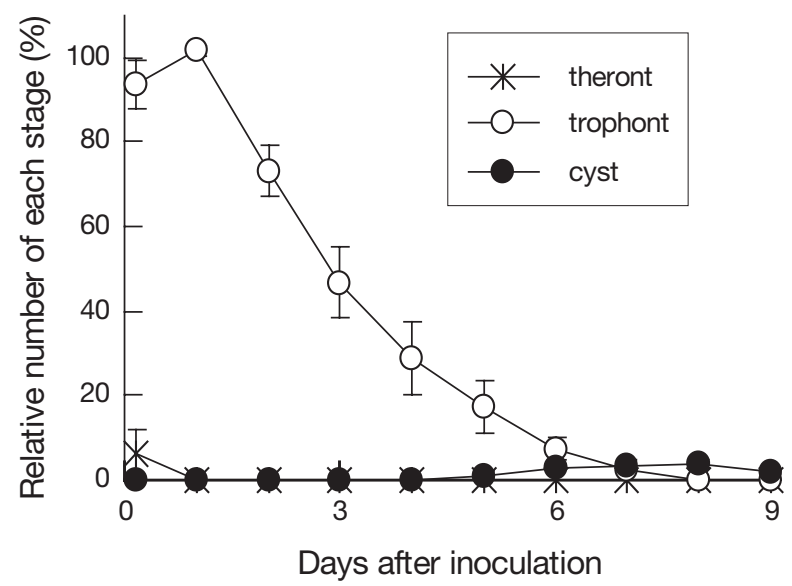

Fig. 2. Cryptocaryon irritans. Transformation and survival in the double-layered medium. Mean percentages of theronts, trophonts and tomont-like cysts in triplicates are shown with standard deviations (vertical bars). The total number of parasites in each culture dish at Hour 4 post inoculation is set at $100 \%$
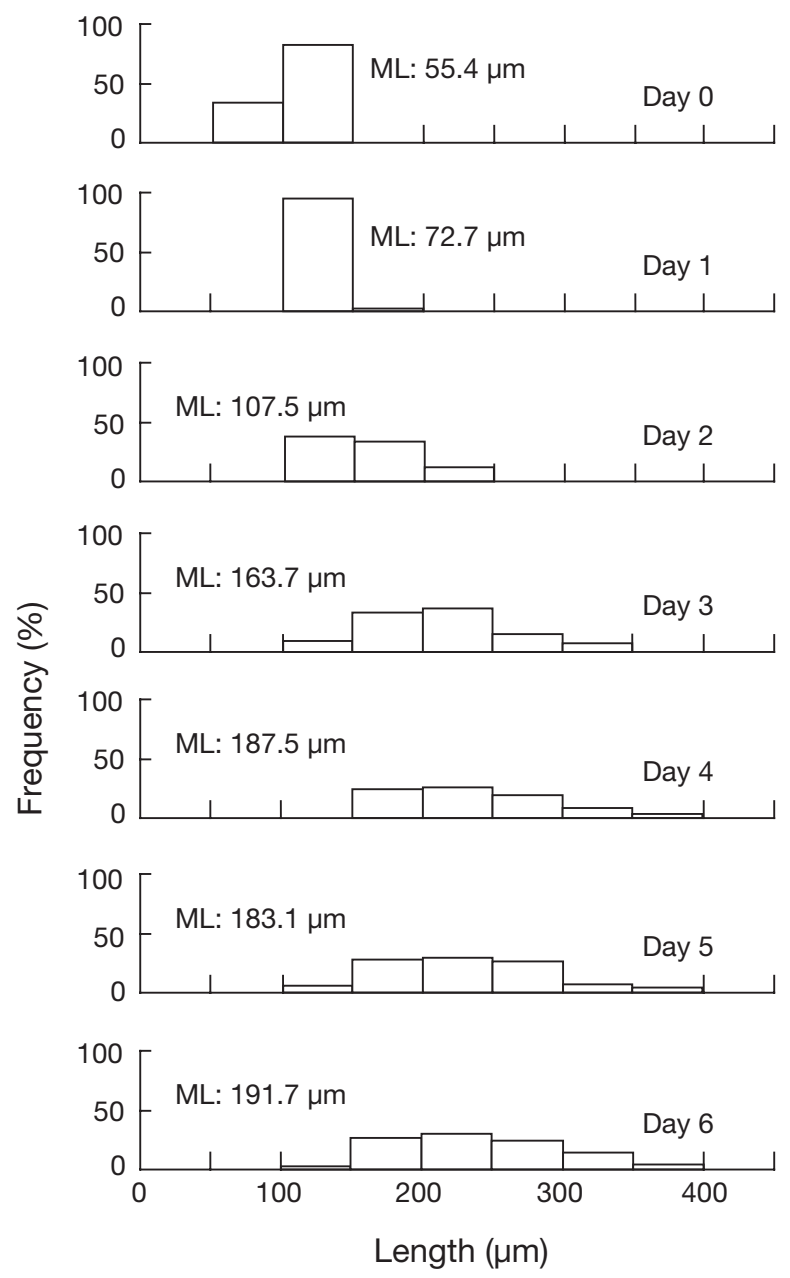

Fig. 3. Cryptocaryon irritans. Growth in the double-layered medium. Mean length (ML) and length-frequency distributions of trophonts are shown for Day 0 to 6 post inoculation

wall around a cell body (Figs. 1F \& 2). Most of the trophonts and cysts died in the medium by Day 10 PI (Fig. 2).

When trophonts were transferred into seawater from the medium, some of them crawled on the substrate as subspherical protomonts (Fig. 1G) and subsequently transformed to tomonts encysted in the cyst wall (Fig. $1 \mathrm{H})$, from which theronts were released (Fig. 1I). The ratios of transformation to tomonts and that of release of theronts were closely associated with the timing of the transfer into seawater. The highest ratios were obtained in trophonts transferred on Day 4 PI; $84 \%$ of trophonts recovered on Day 4 PI transformed to tomonts and, on average, $66.5 \%$ of the trophonts released theronts (Table 1). Tomont-like cysts formed in the medium also released theronts at high ratios, when they were transferred into seawater on Days 4 and 5 PI (Table 1). 
The sizes of tomonts derived from trophonts recovered from in vitro culture medium were smaller than those obtained from the experimentally infected fish; the mean length of the former was approximately 55 to $66 \%$ of that of the latter (Table 1). However, the percentages of theront release were comparable between tomonts that were derived from trophonts recovered from in vitro culture on Day 4 PI and those recovered from infected fish; the percentages of theront release were $66.5 \%$ in the former and $59.0 \%$ in the latter. Moreover, the mean length $( \pm \mathrm{SD})$ was almost identical between theronts derived from in vitro-raised parasites and those derived from parasites recovered from infected fish; they were $50.2 \pm 3.7 \mu \mathrm{m}(\mathrm{n}=45)$ and $52.4 \pm 4.0 \mu \mathrm{m}(\mathrm{n}=45)$, respectively (Student's $t$-test, $\mathrm{p}>0.05$, no significant difference).

In the large-scale culture, inoculated theronts transformed to trophonts and subsequently became encysted as tomonts when transferred into seawater, similar to those from regular-scale cultures. In the first and second experiments, percentages of transformation to tomonts were 11 and $5 \% ; 1736$ and 825 tomonts were obtained from 16200 and 15400 theronts, respectively.

In the experimental infection of fish, where black mollies Poecilia sp. were exposed to theronts released from tomonts produced with the in vitro culture technique, 347 and 335 parasites were recovered from 2 of 3 challenged fish, and 1 fish accidentally escaped from its tank and died. The percentages of parasite recovery were 41 and $39 \%$, respectively, for the 2 fish.

\section{DISCUSSION}

In the present study, Cryptocaryon irritans fully developed in vitro, and, for the first time, its entire life cycle could be followed in the absence of a host fish; theronts transformed to trophonts and grew in doublelayered medium, and, when transferred to seawater, trophonts recovered from medium transformed to encysted tomonts and subsequently released theronts. Moreover, theronts produced with the in vitro culture technique were infective to fish. Infection ratios of theronts produced with the in vitro culture technique were approximately $40 \%$, which compares well with the infection ratio of $40.4 \%$ in a previous experimental infection, in which black mollies Poecilia sp. were challenged by a method similar to the present one (Yoshinaga \& Dickerson 1994)

There have been several trials of in vitro cultures of Cryptocaryon irritans and Ichthyophthirius multifiliis, which is the freshwater counterpart of C. irritans and has been much more intensively studied. Theronts of C. irritans were recently transformed in vitro to trophonts on tryptic soy agar blocks in a mixture of seawater, L-15 medium and FCS (Yambot \& Song 2004). Theronts of I. multifiliis developed to some extent in tissues excised from fish (Xu et al. 2000),

Table 1. Cryptocaryon irritans. Comparisons of percentages of transformation to tomonts and theront release, and of tomont size of parasitic ciliates raised in in vitro culture medium or recovered from experimentally infected fish. n.m.: not measured. Different letters represent significant differences $(\mathrm{p}<0.05)$ between parasites obtained at different days post-inoculation (PI). For statistical analyses of ratios (percentages), ratios obtained from 3 repetitions were subjected to arcsine root transformation and subsequently to ANOVA and post hoc Tukey's multiple comparison test. For analyses of tomont length, lengths of tomonts obtained in the 3 repetitions were pooled and subjected to ANOVA and post hoc Tukey's multiple comparison test

\begin{tabular}{|c|c|c|c|c|c|}
\hline Parasite stage and origin & Days PI & $\begin{array}{l}\text { Trophonts that transformed } \\
\text { to encysted tomonts }(\%) \\
\text { Mean (range) }\end{array}$ & & $\begin{array}{l}\text { h of encysted } \\
\text { nonts }(\mu \mathrm{m}) \\
\text { Mean } \pm \mathrm{SD}\end{array}$ & $\begin{array}{l}\text { Trophonts or tomont-like } \\
\text { cysts that released theronts } \\
(\%) \text { Mean (range) }{ }^{*}\end{array}$ \\
\hline $\begin{array}{l}\text { Trophonts recovered from } \\
\text { medium }\end{array}$ & $\begin{array}{l}2 \\
3 \\
4 \\
5\end{array}$ & $\begin{array}{c}0^{\mp} \\
8.6(2.4-19.3)^{\mathrm{a}} \\
84.0(81.5-85.9)^{\mathrm{b}} \\
50.2(27.9-70.6)^{\mathrm{c}}\end{array}$ & $\begin{array}{c}14 \\
164 \\
65\end{array}$ & $\begin{array}{l}149 \pm 27.0^{\mathrm{a}} \\
185 \pm 35.9^{\mathrm{b}} \\
151 \pm 37.4^{\mathrm{a}}\end{array}$ & $\begin{array}{c}0^{\mp} \\
5.6(2.0-12.3)^{\mathrm{a}} \\
66.5(60.2-70.4)^{\mathrm{b}} \\
28.4(11.5-41.2)^{\mathrm{a}}\end{array}$ \\
\hline $\begin{array}{l}\text { Tomont-like cysts formed } \\
\text { in medium }\end{array}$ & $\begin{array}{l}4 \\
5 \\
7\end{array}$ & & $\begin{array}{c}13 \\
32 \\
111\end{array}$ & $\begin{array}{l}270 \pm 59.8^{\mathrm{ab}} \\
255 \pm 66.3^{\mathrm{a}} \\
288 \pm 61.4^{\mathrm{b}}\end{array}$ & $\begin{array}{c}\quad 84.6^{\ddagger} \\
68.2(56.3-85.7)^{\mathrm{a}} \\
21.2(12.5-28.3)^{\mathrm{b}}\end{array}$ \\
\hline 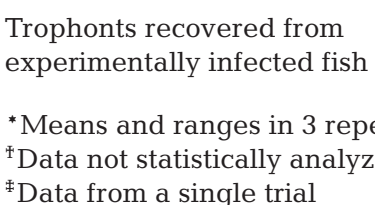 & $\begin{array}{l}\text { ons } \\
\text { gecause }\end{array}$ & $\begin{array}{l}\text { n.m. } \\
\text { no variance }\end{array}$ & 42 & $270 \pm 27.7$ & $59.0^{\ddagger}$ \\
\hline
\end{tabular}


survived longer in Eagle's minimum essential medium than in freshwater (Elkless \& Matthews 1993) and transformed to trophonts when given an Epitheliosa Papulosum Cyprini (EPC) cell line as a substrate (Nielsen \& Buchmann 2000). However, these accomplishments in methods for the culture of both $C$. irritans and $I$. multifiliis were limited to incomplete growth and transformation of parasites under in vitro conditions.

Although the survival rate of parasites in the present in vitro culture medium was not high, roughly $30 \%$ of the inoculated parasites were still alive on Day 4 PI (Fig. 1), 66.5\% of the parasites recovered on Day 4 PI released theronts (Table 1), and the number of theronts released from tomonts is known to be up to 200 theronts per tomont (Colorni 1985). If the value of 100 theronts per tomont is given as the mean number of released theronts, total yield of theronts from 1 theront in the present technique is estimated as ca. 20 by a simple arithmetic calculation. However, we have not succeeded in stably executing the parasite life cycle in vitro using the present technique: parasites were damaged when collected from the medium and the concentration of theronts by centrifugation and filtration decreased their viability (data not shown). Live fish are currently necessary to produce theronts to be inoculated into medium. However, our new technique is an important advance. Even the present in vitro culture technique enables direct and continuous observation of the development and behaviour of Cryptocaryon irritans using an inverted microscope. This will be of much help in studies of the biology and host-parasite interaction of $C$. irritans. Most chemotherapies against C. irritans target the free-living stages, namely, protomonts, tomonts and theronts. Chemotherapy targeting the parasitic stage has not been developed. This is partly because live fish infected with the parasite must be used for primary drug screening. The present culture technique may enable in vitro screening and assist with future drug development for C. irritans.
Acquired immunity of fish against Cryptocaryon irritans has been demonstrated (Yoshinaga \& Nakazoe 1997). If the mass production of theronts of the parasite were possible, it could lead to the development of an inactivated vaccine against the parasite.

Acknowledgements. This study was supported in part by a Grant-in-Aid for Scientific Research (No. 16580145) from the Ministry of Education, Science, Sports and Culture of Japan.

\section{LITERATURE CITED}

Colorni A (1985) Aspects of the biology of Cryptocaryon irritans and hyposalinity as a control measure in cultured gilthead sea bream Sparus aurata. Dis Aquat Org 1: 19-27

Colorni A, Burgess PJ (1997) Cryptocaryon irritans Brown, 1951, the cause of 'white spot disease' in marine fish: an update. Aquar Sci Conserv 1: 217-238

Dickerson HW (2006) Ichthyophthirius multifiliis and Cryptocaryon irritans (phylum Ciliophora). In: Woo PKT (ed) Fish diseases and disorders, Vol 1. Protozoan and metazoan infections, 2nd edn. CAB International, Wallingford, p 116-153

Ekless LM, Matthews RA (1993) Ichthyophthirius multifiliisaxenic isolation and shot-term maintenance in selected monophasic media. J Fish Dis 16:437-447

Nielsen CV, Buchmann RJ (2000) Prolonged in vitro cultivation of Ichthyophthirius multifiliis using an EPC cell line as substrate. Dis Aquat Org 42: 215-219

Xu DH, Klesius PH, Shoemaker CA, Evans JJ (2000) The early development of Ichthyophthirius multifiliis in channel catfish in vitro. J Aquat Anim Health 12: 290-296

Yambot AV, Song YL (2004) Short term in vitro culture of Cryptocaryon irritans, a protozoan parasite of marine fishes. Fish Pathol 39:175-181

Yoshinaga T (2001) Effects of high temperature and dissolved oxygen concentration on the development of Cryptocaryon irritans (Ciliophora) with a comment on the autumn outbreaks of cryptocaryoniasis. Fish Pathol 36: 231-235

Yoshinaga T, Dickerson HW (1994) Laboratory propagation of Cryptocaryon irritans on a saltwater-adapted Poecilia hybrid, the black molly. J Aquat Anim Health 6: 197-201

Yoshinaga T, Nakazoe J (1997) Acquired protection and production of immobilization antibody against Cryptocaryon irritans (Ciliophora, Hymenostomatida) in mummichog (Fundulus heteroclitus). Fish Pathol 32: 229-230

Submitted: January 10, 2007; Accepted: August 6, 2007

Proofs received from author(s): November 1, 2007
Editorial responsibility: Dieter Steinhagen,

Hannover, Germany 